\title{
The Behavioral Intention in Accessing Digital Healthcare Information on Social Media
}

\author{
Philomina P. Ofori" ${ }^{* 1,2}$, Ethel Asante Antwi, $\mathrm{PhD}^{2}$, Adelaide Oduro-Asante ${ }^{2}$ \\ ${ }^{1}$ School of Management, Jiangsu University, 301 Xuefu Road, Zhenjiang, 212013, China \\ ${ }^{2}$ Ghana Communication Technology University, Ghana
}

\section{Article Info}

Volume 8, Issue 6

Page Number : 510-521

\section{Publication Issue}

November-December-2021

\section{Article History}

Accepted : 15 Dec 2021

Published : 30 Dec 2021

\section{ABSTRACT}

Purpose: Social media healthcare is becoming increasingly important in healthcare as many individuals seek healthcare information and support through online social media platforms. Social media healthcare is an emerging field; however, it is not clear what factors influence an individual's acceptance of its usage. Based on the Unified Theory of Acceptance and Use of Technology (UTAUT) model, the study explores the factors that influence acceptance of social media usage for healthcare by consumers.

Design/Method: Using a purposive sampling approach, the researchers sent a validated questionnaire link to participants through social media platforms. A total of 260 responses from respondents were analyzed using SmartPLS3.

Results: Analysis of the data revealed that performance expectancy, effort expectancy, social influence, and satisfaction significantly impact consumers' behavior intention to embrace social media health information. The effect of four identified factors: "PE" ( $\beta=.415$, t-value $=3.194, \mathrm{p}<.001)$, "EE" $(\beta=-$. 3.98 , $\mathrm{t}$-value $=2.443, \mathrm{p}<.015)$, "SI" $(\beta=.593$, $\mathrm{t}$-value $=3.774, \mathrm{p}<.000)$, "SAT" $(\beta=.312, \mathrm{t}$-value $=2.676, \mathrm{p}<.008)$.

Conclusions: Social media health is vital to healthcare seekers, especially where it enables consumers to manage their health. On implication, the study provides healthcare givers and professionals insight on how to approach and advance social media healthcare education and interaction with consumers.

Keywords : Healthcare, social media, satisfaction, UTAUT model

\section{INTRODUCTION}

Social media (SM) features and rapid online communication have made these platforms popular among many users [1], [2]. The myriad benefits that SM offers introduce unique opportunities for both individuals and organizations [3], [4]. Chief among these benefits is the ease and availability of collaboration and information sharing [5]. This medium has become part of individuals' lives, with many people using it regularly for daily activities [6]. Many mobile phone users use one or more SM platforms, allowing users to disseminate information and experiences easily [4], [7]. SM has become a prime 
avenue for facilitating communication between users and their friends, family, and online community. Among the information consumers seek on SM is healthcare-related information. Social media healthcare is defined as patients seeking healthcare information and support through online social media platforms. Health groups and organizations provide education and counseling services directly to consumers through SM. Some health seekers use SM platforms to find quick health information from unofficial sources [8]. In addition, health seekers frequently use SM platforms to find support from others [8]. Health information sharing by unofficial groups and healthcare providers has opened a new door for participatory healthcare [9]. Social media's participatory nature connects patients with individuals with similar health conditions and can introduce individuals to useful information that enables them to manage their health [10]. In recent years, a number of studies on social media healthcare have been conducted. [11] investigated how healthcare professionals intend to use social media in their daily work. According to the survey, clinicians use social media for practical purposes. [12] research into the impact of social media on healthcare policy and found that it has grown into a rapidly growing communication medium that may be used to share health policy decisions. It was also emphasized that effective distribution systems, particularly for health coverage, should have a strategic goal that is guided by the viewpoints of patients. [13] evaluated the impact of social media on dental patients in Saudi Arabia. The conclusions of the SAS-based study indicated that patients pay attention to healthcare facilities that have a social media presence. A similar study [14] investigated how social media could aid diabetes patients in managing their condition. Using a core group, it was discovered that social media communication can help enhance diabetes treatment by improving communication outside of clinic appointments. The researchers concluded that using social media for these purposes enables diabetics to control their condition on their own. Social media, according to studies, provides an environment where people with comparable illnesses interact and aid one another. Despite the fact that healthcare practitioners and public health institutions are still hesitant about using social media for healthcare purposes, research shows that social media users are concerned about health information [15]. This notwithstanding, relatively scant research exists on social media health information seeking behavior intention. Technological acceptance theories and models, such as the Unified Theory of Acceptance and Use of Technology (UTAUT) model, are gaining popularity in the digital health field [16]-[18]. Using the UTAUT model, this study explores the factors affecting consumer acceptance of SM health information in Ghana. Traction

\section{LITERATURE REVIEW AND HYPOTHESIS DEVELOPMENT}

\section{A. Unified Theory of Acceptance and Use of Technology (UTAUT)}

The Unified Theory of Acceptance and Use of Technology (UTAUT), developed as a synthesis of eight separate technology acceptance models, is one of the models that researchers in various research disciplines have used to measure the intention to engage with technology. The original UTAUT model was comprised of six primary constructs. Performance expectancy $(\mathrm{PE})$ is described as a person's belief that by utilizing the system, he or she would be able to improve their work performance [19]; effort expectancy (EE) is a measure of how easy a system is to use; the degree to which a person believes important individuals feel he or she should adopt the new system is referred to as social influence (SI); the degree to which a person feels that an organization designed infrastructure exists to facilitate the usage of a system is known as facilitating conditions (FC) [19]; behavior intention (BI) and use behavior (UB). Additionally, there were four moderators: gender, age, experience, 
and voluntariness of use. The first three constructs: PE, $\mathrm{EE}$, and SI, were used as predictors of behavioral intention, the expressed intent to interact with new technology, and FC was the predictor for UB. All the model constructs were predictors of technology acceptance [19]. In the original model, FC was directly linked with UB, and PE, EE, and SI were directly connected with BI. In our study, PE, EE, and SI were used with BI, so FC was taken out of our study. Satisfaction (SAT) was integrated to assess how it will influence consumers' BI to use SM for healthcare.

According to research, consumers utilize the internet anytime they see additional benefits, such as greater access to a wider variety of health care information and the opportunity to communicate with many other users on a network [5]. It is revealed that social media utilization seems to have a substantial link with performance expectations [20]. Social influence and attitudes, according to other studies, have distinct effects on various platforms' usage [21]. Studies have shown that a person's satisfaction with social media health information is crucial to consumers' ability to keep their healthcare [22]. In similar research, it has been ascertained that digital transformation and behavioral intention have a significant influence on the acceptance and adoption of digital health among members [23]. Investigating the relationship between behavior intention and system utilization has discovered that behavioral intent is a strong predictor of user acceptance [24]. Studies have shown that technology performance expectancy positively influences consumers' behavior intentions [19], [25][27]. In other studies, it is confirmed that social influence impacts consumers' behavioral intentions [19], [28], [29]. Likewise, it has been indicated that effort expectancy has a positive relationship with behavior intention [19], [26], [30]. Based on these criteria, this study utilizes a modified UTAUT model, borrowing the following hypotheses from its original formulation:
H1: Performance expectancy is a predicting factor of consumers' BI to use social media for healthcare purposes.

H2: Effort expectancy has a significant effect on consumers' BI to use social media for healthcare purposes.

H3: Social influence relates positively to consumers' BI to use social media for healthcare purposes.

\section{B. Healthcare Satisfaction (SAT)}

Patient satisfaction in healthcare delivery; has been recognized as an essential metric for health care quality assessment, and it is a vital part of performance management and clinical efficacy [31]. Customer satisfaction can be assessed as a client's pleasure, and it's always regarded as the main factor in a company's success [32]. It is assumed that healthcare systems' performance relies on customer satisfaction [33]. In the healthcare industry, patient satisfaction has an impact on profit [34]. It has been shown that satisfaction with digital health information positively impacts patients' trust [35]. Satisfaction is a critical factor for predicting consumers' BIs toward accepting information technology (Koufaris and Hampton-Sosa, 2004; Chao, 2019). Consumers' trust in the internet and information from health professionals' services brings satisfaction to patients [38]. Based on this discussion, we hypothesized that:

H4: Consumer satisfaction is a predicting factor of consumers' BI to use social media for healthcare purposes.

\section{Research Methodology}

A. Research study design, settings, and participants

This was descriptive cross-sectional research that took place in the Accra metropolis. The study used primary data and the responses were obtained from individuals who own smartphones and use one or more social media platforms. The study area was chosen based on the availability of respondents. Based on this, a 
purposive sampling approach was adopted to settle on the study's scope.

\section{B. Material and procedure}

The study's survey questionnaire was adapted from previous studies. The questionnaire consisted of UTAUT model questions from [19] and consumer satisfaction from [39]. The questionnaire was pretested for some time before it was sent out to respondents. The recommendation from the pretest helped the authors amend the questions to meet the study settings requirement. The amended items questionnaire was tested for accuracy, validity, and reliability. Participants were contacted by mobile phone to participate in the survey. A well-structured online questionnaire in English with a link to (Microsoft Form) was sent to participants by the authors and supporting data collectors. The completed questionnaire was imported into excel format. Respondents answered the questionnaire on a 5-point Likert scale with values ranging from strongly disagree (1) to strongly agree (5).

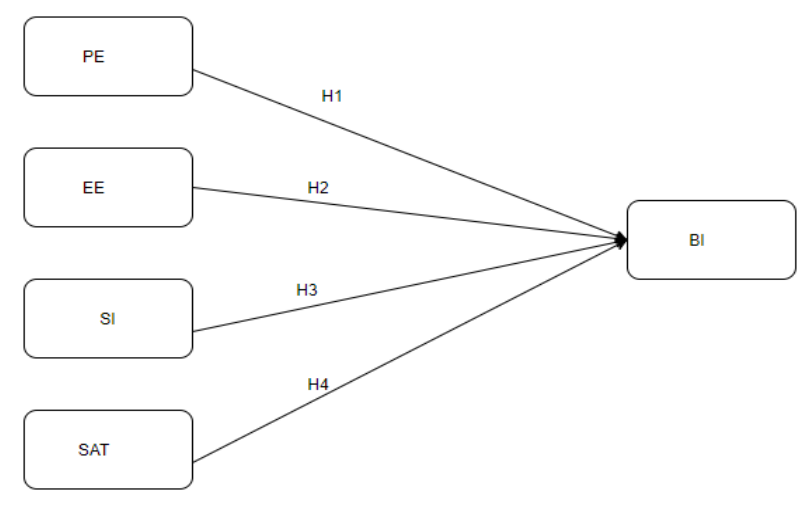

Figure 1. The Research Model

The modified UTAUT model shows the influence of performance expectancy (PE), effort expectancy (EE), social influence (SI), and consumer satisfaction (SAT) on behavior intention (BI). $\mathrm{H} 1$ to $\mathrm{H} 4$ represent the four study hypotheses, indicating the predictive weight of each construct on BI.
C. Model instrument and measurements

Internal consistency Reliability of the data was assessed using Cronbach's alpha (CA) and composite reliability (CR). The assessment of internal consistency reliability was examined to assess the onedimensionality of the entire questionnaire measurements. The convergent validity of the data was measured using factor loadings and average variance extracted (AVE). The CR and AVE for each construct provide coefficients that support the reliability of the survey used for the study [40]. The parameters were measured using indicators designed to elicit responses that were related to the construct [41]. The majority of researchers employ structural equation modeling (SEM) to evaluate data as a measurement statistical method. The original UTAUT model study indicated adopting the "partial least square" path modeling approach [19]. The SmartPLS application software (3.3.0) was used for the path analyses and the hypotheses for the study [23]. The variables' discriminant validity was assessed using [42].

\section{RESULTS}

A. Demographic information of the respondents

Demographic information about the participants is summarized in Table 1 . The results show that the majority of the respondents were $78.8 \%$ males and $21.2 \%$ females. They were grouped into three age categories: most of them were between the ages of 15-25 (72.7\%), 26-35 (21.5), and above 36 (5.8). Marital status was categorized as single or married, and the majority were single (92.3\%), and a small number were married (7.7\%). Respondent educational attainment was classified as either diploma (13.5\%), bachelor's degree (67.7\%), master's (3.5\%), or other certificates (15.3\%). 
Philomina P. Ofori et al Int J Sci Res Sci \& Technol. November-December-2021, 8 (6) : 510-521

Table 1 : Demographic of respondents

\begin{tabular}{lll}
\hline Demographics & $\begin{array}{l}\text { Number } \\
260\end{array}$ & Percentage \% \\
\hline Gender & & \\
Male & 205 & 78.8 \\
Female & 55 & 21.2 \\
Age & & \\
$15-25$ & 189 & 72.7 \\
$26-35$ & 58 & 21.5 \\
36 and above & 34 & 5.8 \\
Marital status & & \\
Single & 240 & 92.3 \\
Married & 20 & 7.7 \\
Educational & & \\
background & & \\
Diploma & 35 & 13.5 \\
Degree & 176 & 67.7 \\
Masters & 9 & 3.5 \\
Other & 40 & 15.3 \\
\hline
\end{tabular}

D. Measurement model evaluation

This model has 26 items and is made up of five observable constructs: PE, EE, SI, SAT, and BI, and out of those total items, 19 were included in the analysis. Factor loadings and average variance were used to determine convergent validity (AVE). The factor loadings $(\lambda)$ ranged from 0.578 to 0.949 , with AVE values for each construct equal to or greater than 0.500 , indicating good convergent validity [43]. Internal consistency reliability was evaluated using Cronbach's alpha (CA) and composite reliability (CR). Each construct had CR values of between 0.750 and 0.847 , with a (CA) value equal to or greater than 0.751 , which indicates that the model meets the standards for reliability [44].

Table 2 : Results of construct reliability and validity

\begin{tabular}{|c|c|c|c|c|c|c|}
\hline \multirow[b]{2}{*}{ Construct } & \multirow[b]{2}{*}{ Items } & \multirow{2}{*}{\multicolumn{2}{|c|}{ Convergent validity }} & \multicolumn{3}{|c|}{ Internal consistency } \\
\hline & & & & Reliability & & \\
\hline & & Factor & & Composite & & \\
\hline & & loadings & Average Variance & Reliability & Cronbach's & HTMT- \\
\hline & & $(\lambda)$ & Extracted (AVE) & $(\mathrm{CR})$ & Alpha (CA) & Less than 1 \\
\hline \multirow[t]{4}{*}{$\mathrm{PE}$} & PE2 & 0.701 & & & & \\
\hline & PE3 & 0.702 & 0.500 & 0.750 & 0.751 & Yes \\
\hline & PE4 & 0.718 & & & & \\
\hline & EE1 & 0.751 & & & & \\
\hline \multirow[t]{4}{*}{$\mathrm{EE}$} & EE2 & 0.718 & & & & \\
\hline & EE3 & 0.613 & 0.527 & 0.847 & 0.848 & Yes \\
\hline & EE4 & 0.765 & & & & \\
\hline & EE5 & 0.769 & & & & \\
\hline \multirow[t]{3}{*}{ SI } & SI5 & 0.840 & & & & \\
\hline & SI6 & 0.618 & 0.508 & 0.753 & 0.747 & Yes \\
\hline & SI7 & 0.661 & & & & \\
\hline \multirow[t]{4}{*}{ SAT } & SAT1 & 0.578 & & & & \\
\hline & SAT2 & 0.771 & 0.584 & 0.845 & 0.849 & Yes \\
\hline & SAT3 & 0.949 & & & & \\
\hline & SAT4 & 0.712 & & & & \\
\hline
\end{tabular}


Philomina P. Ofori et al Int J Sci Res Sci \& Technol. November-December-2021, 8 (6) : 510-521

$\begin{array}{lllllll}\text { BI } & \text { BI1 } & 0.720 & & & & \\ \text { BI2 } & 0.789 & 0.560 & 0.834 & & \text { Yes } \\ \text { BI4 } & 0.840 & & & \\ \text { BI5 } & 0.628 & & & \end{array}$

Legend: $\mathrm{PE}=$ Performance Expectancy, $\mathrm{EE}=$ Effort Expectancy, $\mathrm{SI}=$ Social Influence, $\mathrm{SAT}=$ Satisfaction, $\mathrm{BI}=$ Behavioral intention

\section{Discriminant Validity}

To determine how different one construct was from the others, researchers employed a measure of discriminant validity, cross-loading analysis, and the heterotrait-monotrait (HTMT) ratio test [45]. Table 2 shows the HTMT ratio test results and reveals that all the values are less than 1 , indicating discriminant validity between all constructs.

\section{Structural model assessment}

In this study, the dependent variable was predicted by the independent variables. It was revealed that, $\mathrm{PE}$ has a positive effect on $\mathrm{BI}(\beta=.415, \mathrm{t}$-value $=3.194$, $\mathrm{p}<$ .001). EE negatively correlated but was significant which supported our hypothesis $(\beta=-.3 .98, \mathrm{t}$-value $=$ $2.443, \mathrm{p}<.015)$, SI was positively associated with BI $(\beta$ $=.593, \mathrm{t}$-value $=3.774, \mathrm{p}<.000)$, and SAT positively influenced BI $(\beta=.312$, $\mathrm{t}$-value $=2.676, \mathrm{p}<.008)$. These results showed that all the hypotheses were supported (see Table 3). Multicollinearity was tested by using variance inflation factors (VIF) with a threshold of 5 [46]. The results show that multicollinearity was not a major issue in this study (see Table 3).

E. Predictive relevance and accuracy of the model The PLS-SEM analysis results in Table 3 show that the R2 of the endogenous construct BI was 0.731, indicating that the model accounts for $73 \%$ of the variance in BI. The adjusted R2 was nearly the same at 0.727. Effect size f2 values were between 0.181 and 0.502 , indicating a medium and large effect of the exogenous latent variables [47]. The cross-validated redundancy for BI was greater than zero Q2 (0.315), indicating a valid construct. The effect size indicates that the model has high predictive relevance for BI [44]. Furthermore, the standard root means square residual (SRMR) was used to assess the model fit [48]. The value of 0.063 was less than 0.08 , which indicates that it is indeed a good fit [49].

Table 3: Path coefficient and hypotheses testing

\begin{tabular}{|c|c|c|c|c|c|c|c|c|}
\hline \multirow[b]{2}{*}{ Hypothesis } & \multirow[b]{2}{*}{ Path } & \multicolumn{2}{|l|}{ Path } & \multicolumn{5}{|l|}{ P- } \\
\hline & & Coefficient & T-Statistics & values & Remarks & Construct & VIF & $\mathrm{f}^{2}$ \\
\hline $\mathrm{HI}$ & $\mathrm{PE}->\mathrm{BI}$ & .415 & 3.194 & .001 & Supported & PE & 2.074 & 0.308 \\
\hline H2 & $\mathrm{EE}->\mathrm{BI}$ & -.398 & 2.443 & .015 & Supported & $\mathrm{EE}$ & 2.973 & 0.198 \\
\hline H3 & SI $->\mathrm{BI}$ & .593 & 3.774 & .000 & Supported & S1 & 2.610 & 0.502 \\
\hline H4 & SAT-> BI & 312 & 2.676 & .008 & Supported & SAT & 2.001 & 0.181 \\
\hline \multicolumn{4}{|c|}{ Cross validated redundancy } & \multicolumn{2}{|c|}{ Effect Size } & \multicolumn{3}{|c|}{$\begin{array}{l}\text { Coefficient of } \\
\text { determination }\end{array}$} \\
\hline Construct & SSO & SSE & $\begin{array}{l}\mathrm{Q}^{2} \\
(=1 \mathrm{SSE} / \mathrm{SSO})\end{array}$ & & & $\mathrm{R}^{2}$ & \multicolumn{2}{|c|}{ Adjusted $\mathrm{R}^{2}$} \\
\hline BI & 1040.000 & 712.685 & 0.315 & & & 0.731 & 0.727 & \\
\hline
\end{tabular}


Legend: $\mathrm{BI}=$ Behavioral intention, $\mathrm{EE}=$ Effort expectancy, $\mathrm{PE}=$ Performance expectancy, $\mathrm{SAT}=$ Satisfaction, $\mathrm{SI}$ = Social Influence

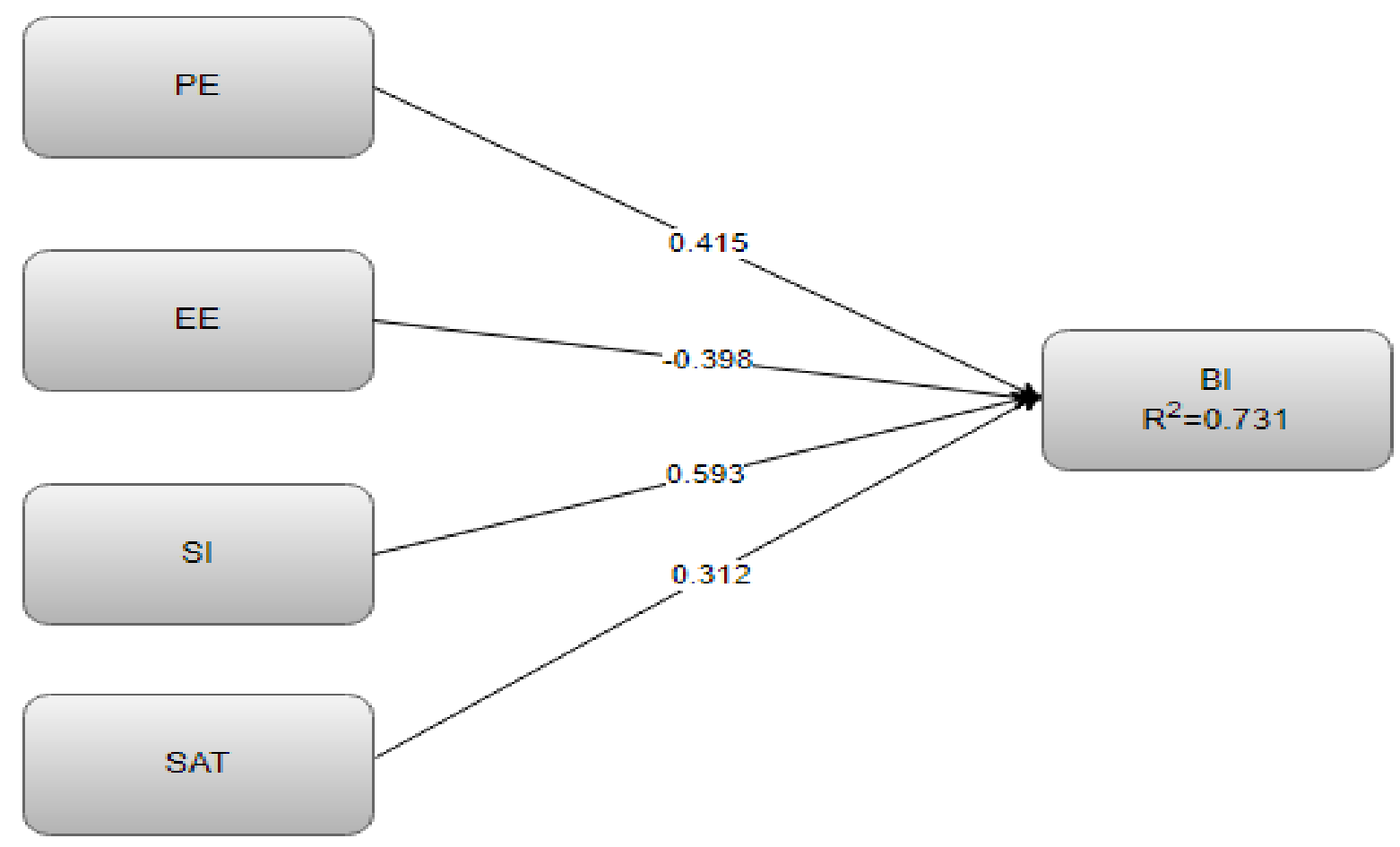

Figure 2. The Measurement Model Results

The model predicts 73\% of BI's variance using PE, EE, SI, and SAT. Predictive weights between questions and variables $(\lambda)$ and between the independent and dependent variables $(\beta)$ are shown along the line.

\section{Discussion}

This study looked at the elements that influence consumers' intentions to acquire healthcare information via social media. This study provides insight into ways to improve social media healthcare services and health awareness among health consumers. First, the results show that consumers expect a SM healthcare platform's performance to have functionalities that will enable them to appreciate the platform, which will lead to their decision to use it for healthcare purposes. This aligns well with prior studies, which have shown that PE has a crucial effect on consumers' behavior intentions [19], [50], [51][52]. The results from the study highlight that, for consumers to adopt a social media health platform, they must understand how the system can improve their health conditions and enable them to manage their health. Second, as hypothesized, effort expectancy (EE) predicts consumers' behavior intention to use social media for healthcare. The effort consumers expect to exert using SM, whether high or low, does not affect their decision towards SM acceptance. The results mean that increasing the amount of anticipated effort required to use SM for healthcare decreases the likelihood that consumers will use SM. It also implies that the more effort a consumer expects to exert, the lower their intention to use social media for healthcare. Interestingly, effort expectancy has a significant effect on consumers' behavior intentions to use social media for healthcare. The findings of the current study are consistent with [19], [26], [30]. Third, the results show that social influence (SI) significantly affects consumer 
healthcare behavior. When consumers have SM, platforms recommended to them by trusted sources, they are more likely to consider using the platform seriously. This is consistent with previous research indicating that SI influences behavior intentions [19], [28], [29], [52], [53]. The influence of prominent social figures is a strong driver of the adoption of new SM platforms by the larger population. Fourth, consumer satisfaction (SAT) significantly affected the consumer's intention to use social media healthcare platforms. In other words, when consumers are satisfied with the platform's features accompanied by the information and services rendered on SM healthcare platforms, they are more likely to adopt these platforms for regular use. This study backs up previous findings [37], [54], [55]. Many consumers are internet savvy and have expectations regarding their SM experiences. Not only should the information provided on platforms be relevant, but the overall experience of finding that information should be pleasant and satisfying. PE, EE, SI, and SAT predict consumers' intent to use social media platforms for healthcare information. Thus, increasing consumers' intentions through PE, EE, SI, and SAT is an effective way of encouraging consumers to use healthcare information on social media platforms. The study findings indicate that a high degree of PE, SI, and SAT will result in a high probability that consumers will use the SM platform for healthcare information.

\section{A. Managerial Implications and Theoretical contributions}

\section{1) Managerial Implications}

The purpose of this study is to examine the factors that impact people's intentions to utilize social media for healthcare information. Importantly, information about healthcare on social media could enhance customer expectations. As a result, healthcare organizations and professionals that provide information and education on social media should ensure that their efforts are focused on the requirements of their customers. Interactions, videos, and texts would all be necessary to maintain customer involvement. Medical organizations and social media healthcare providers might hire specialists to guarantee that platform design fulfills the demands of customers. Finally, health providers might give incentives to existing platform users in order to attract new customers.

\section{2) Theoretical contributions}

Only a few studies with Ghanaian subjects have been conducted. Most of the research has focused on healthcare practitioners who use digital technologies in their practices, but little has been done to investigate consumer acceptability of digital healthcare, particularly on social media. This study, unlike other studies on social media healthcare, emphasizes the important influence of PE, EE, SI, and SAT on behavioral intentions. The research provides a thorough knowledge of the elements that impact what people think about while looking for healthcare information. With the introduction of SAT to the constructs of the UTAUT model, we show that consumers pay close attention to their platforms' experiences and that consumer satisfaction is essential in influencing their decision to utilize SM healthcare platforms.

\section{CONCLUSION}

In the lives of individuals in society, social media usage is taking a new turn. Thus, the intention of individuals toward social media healthcare information is positive, which would improve their personal health management. We posit that satisfaction contributes to individuals' healthcare information behavior intentions on social media platforms. The results imply that consumers are more likely to use social media platforms if they provide consumers with advantages, such as giving important health information. With the 
new construct introduced, it impacted the predictive variance of behavior intention. This study enhances the literature on social media healthcare in developing countries. The model used has implications for decision-making among social media healthcare providers.

\section{VII.LIMITATIONS OF THE STUDY}

The current study has some limitations: this study was conducted in Ghana, where social media healthcare is at its infant stage, hence the small sample size. Again, participants replied to the survey based on how they felt about the questions asked, their level of expertise, and their opinions about social networking sites. As a result, the findings of this study may not be applicable to the whole population. Most importantly, the integrity of the information obtained, on the other hand, was adequate for the topic, which had a positive effect on the study's findings.

\section{REFERENCES}

[1]. H. Uittenhout, "The Use and Effect of Social Media in Health Communication About Common Head Lice," Unversity of Twente, 2012.

[2]. G. LaBarge and M. Broom, "Social Media in Primary Care," Sci. Med. | Featur. Ser., no. April, 2019.

[3]. V. Gamache-OLeary and G. Grant, "Social Media in Healthcare," Proc. 50th Hawaii Int. Conf. Syst. Sci., pp. 3774-3783, 2017, doi: 10.24251/hicss.2017.456.

[4]. S. C. Chen and C. P. Lin, "Understanding the effect of social media marketing activities: The mediation of social identification, perceived value, and satisfaction," Technol. Forecast. Soc. Change, vol. 140, no. July 2018, pp. 22-32, 2019, doi: 10.1016/j.techfore.2018.11.025.

[5]. I. Puspitasari and A. Firdauzy, "Characterizing consumer behavior in leveraging social media for e-patient and health-related activities," Int. J. Environ. Res. Public Health, vol. 16, no. 18, 2019, doi: 10.3390/ijerph16183348.

[6]. M. C. Sendall, L. K. McCosker, P. Crane, B. Rowland, M. Fleming, and H. C. Biggs, "Using Facebook for health promotion in 'Hard-toReach' truck drivers: qualitative analysis," J. Med. Internet Res., vol. 20, no. 11, pp. 1-11, 2018, doi: 10.2196/jmir.9689.

[7]. L. A. Siegmund, “ Like Us on Facebook ${ }^{\circledR}$ ' : Nursing in a World of Social Media," J. Radiol. Nurs., vol. 38, no. 3, pp. 183-187, 2019, doi: 10.1016/j.jradnu.2019.06.003.

[8]. S. Atique et al., "Lessons Learnt from a MOOC about Social Media for Digital Health Literacy," 978-1-4577-0220-4/16/@2016 IEEE, pp. 56365639, 2016.

[9]. C. S. Bond, M. Merolli, and O. H. Ahmed, Patient Empowerment Through Social Media. Elsevier Inc., 2016.

[10]. Q. L. Chen and Z. H. Zhou, "Unusual formations of superoxo heptaoxomolybdates from peroxo molybdates," Inorg. Chem. Commun., vol. 67, no. 3, pp. 95-98, 2016, doi: 10.1016/j.inoche.2016.03.015.

[11]. J. Tunnecliff et al., "The Acceptability Among Health Researchers and Clinicians of Social Media to Translate Research Evidence to Clinical Practice: Mixed-Methods Survey and Interview Study Corresponding Author:," vol. 17, 2015, doi: 10.2196/jmir.4347.

[12]. D. Roland, "Social Media, Health Policy, and Knowledge Translation," J. Am. Coll. Radiol., vol. 15, no. 1, pp. 149-152, 2018, doi: 10.1016/j.jacr.2017.09.009.

[13]. A. Alalawi, H. Aljuaid, and Z. S. Natto, "The Effect Of Social Media On The Choice Of Dental Patients: A Cross-Sectional Study In The City Of Jeddah , Saudi Arabia," 2019.

[14]. F. S. Malik, N. Panlasigui, J. Gritton, H. Gill, J. P. Yi-Frazier, and M. A. Moreno, "Adolescent perspectives on the use of social media to 
support type 1 diabetes management," J. Med. Internet Res., vol. 21, no. 6, 2019, doi: 10.2196/12149.

[15]. R. Bannor, A. K. Asare, and J. N. Bawole, "Effectiveness of social media for communicating health messages in Ghana," Health Educ., vol. 117, no. 4, pp. 342-371, 2017, doi: 10.1108/HE-06-2016-0024.

[16]. O. I. Obasola and O. M. Agunbiade, "Online Health Information Seeking Pattern Among Undergraduates in a Nigerian University," SAGE Open, vol. 6, no. 1, 2016, doi: $10.1177 / 2158244016635255$.

[17]. S. S. L. Tan and N. Goonawardene, "Internet health information seeking and the patientphysician relationship: A systematic review," J. Med. Internet Res., vol. 19, no. 1, 2017, doi: 10.2196/jmir.5729.

[18]. Z. Lulin, J. Owusu-Marfo, H. A. Antwi, and X. $\mathrm{Xu}$, "The Contributing Factors to Nurses' Behavioral Intention to Use Hospital Information Technologies in Ghana," SAGE Open Nurs., vol. 6, no. 301, 2020, doi: $10.1177 / 2377960820922024$.

[19]. V. Venkatesh, M. G. Morris, G. B. Davis, and F. D. Davis, "User Acceptance of Information Technology: Toward a Unified View," MIS Q., vol. 27, no. 3, pp. 425-478, 2003, doi: 10.1016/j.inoche.2016.03.015.

[20]. K. Praveena and S. Thomas, "Explaining user acceptance and usage of social networking sites: The role of trust, social connectedness and visibility in extending UTAUT2," Int. J. Manag. Pract., vol. 11, no. 3, pp. 318-334, 2018, doi: 10.1504/IJMP.2018.092855.

[21]. N. Wang and Y. Sun, "Social influence or personal preference? Examining the determinants of usage intention across social media with different sociability," Inf. Dev., vol. 32, no. 5, pp. 1442-1456, 2016, doi: $10.1177 / 0266666915603224$.
[22]. Z. Wang, J. Wang, and A. Maercker, "Program Use and Outcome Change in a Web-Based Trauma Intervention: Individual and Social Factors.," J. Med. Internet Res., vol. 18, no. 9, p. e243, Sep. 2016, doi: 10.2196/jmir.5839.

[23]. R. Hoque and G. Sorwar, "Understanding Factors Influencing the Adoption of mHealth by the Elderly: An Extension of the UTAUT Model," Int. J. Med. Inform., vol. 101, pp. 75-84, 2017, doi: 10.1016/j.ijmedinf.2017.02.002.

[24]. V. Venkatesh and F. D. Davis, "A Theoretical extension of the Technology Acceptance Model: Four longitudinal field studies," Manage. Sci., vol. 46, no. 2, pp. 186-204, 2000, doi: 10.1287/mnsc.46.2.186.11926.

[25]. A. Alsyouf and A. K. Ishak, "Understanding EHRs continuance intention to use from the perspectives of UTAUT: Practice environment moderating effect and top management support as predictor variables," Int. J. Electron. Healthc., vol. 10, no. 1-2, pp. 24-59, 2018, doi: 10.1504/IJEH.2018.092175.

[26]. I. Puspitasari and A. Firdauzy, "Characterizing consumer behavior in leveraging social media for e-patient and health-related activities," Int. J. Environ. Res. Public Health, vol. 16, no. 18, pp. 3-5, 2019, doi: 10.3390/ijerph16183348.

[27]. H. Wang, D. Tao, N. Yu, and X. Qu, "Understanding consumer acceptance of healthcare wearable devices: An integrated model of UTAUT and TTF," vol. 139, no. October 2019, 2020, doi: 10.1016/j.ijmedinf.2020.104156.

[28]. L. L. Zhou et al., ““ Assessment of the social influence and facilitating conditions that support nurses ' adoption of hospital electronic information management systems ( HEIMS ) in Ghana using the unified theory of acceptance and use of technology ( UTAUT ) model ", " pp. 1-9, 2019.

[29]. R. P. Francis, “Examining healthcare providers' acceptance of data from patient self-monitoring 
devices using structural equation modeling with the UTAUT2 model," Int. J. Healthc. Inf. Syst. Informatics, vol. 14, no. 1, pp. 44-60, 2019, doi: 10.4018/IJHISI.2019010104.

[30]. Z. Lulin, J. Owusu-Marfo, H. Asante Antwi, M. O. Antwi, and X. Xu, "Nurses' Readiness in the Adoption of Hospital Electronic Information Management Systems in Ghana: The Application of the Structural Equation Modeling and the UTAUT Model," SAGE Open, vol. 10, no. 2, 2020, doi: 10.1177/2158244020931814.

[31]. M. Roham, A. R. Gabrielyan, and N. P. Archer, "Artificial Intelligence in Medicine Predicting the impact of hospital health information technology adoption on patient satisfaction," Artif. Intell. Med., vol. 56, no. 2, pp. 123-135, 2012, doi: 10.1016/j.artmed.2012.08.001.

[32]. W. Mehmood and O. Shafiq, "Impact of Customer Satisfaction, Service Quality, Brand Image on Purchase Intention," J. Mark. Consum. Res. J., vol. 15, 2015.

[33]. J. Kissi, B. Dai, C. S. K. Dogbe, J. Banahene, and O. Ernest, "Predictive factors of physicians' satisfaction with telemedicine services acceptance," Health Informatics J., 2019, doi: $10.1177 / 1460458219892162$.

[34]. J. P. Richter and A. S. Kazley, "Social media: How hospital facebook activity may influence patient satisfaction," Health Mark. Q., pp. 1-9, 2020, doi: 10.1080/07359683.2020.1713573.

[35]. R. Liu, R. Zhang, and X. Lu, "An empirical study on the relationship between the satisfaction of internet health information and patient compliance-Based on trust perspective," ACM Int. Conf. Proceeding Ser., pp. 61-66, 2018, doi: 10.1145/3268891.3268900.

[36]. M. Koufaris and W. Hampton-Sosa, "The development of initial trust in an online company by new customers," Inf. Manag., vol. 41, no. 3, pp. 377-397, 2004, doi: 10.1016/j.im.2003.08.004.
[37]. C.-M. Chao, "Factors determining the behavioral intention to use mobile learning: An application and extension of the UTAUT model," Front. Psychol., vol. 10, no. 1652, pp. 114, 2019, doi: 10.3389/fpsyg.2019.01652.

[38]. E. Simou, "Health information sources: trust and satisfaction," Int. J. Healthc., vol. 2, no. 1, 2015, doi: 10.5430/ijh.v2n1p38.

[39]. A. Bhattacherjee, "Understanding Information SYstems Continuance: An ExpectationConfirmation Model," MIS Q., vol. 25, no. 3, pp. 351-370, 2001.

[40]. T. A. Mohammed and S. M. Pandhiani, "Analysis of Factors Affecting Student Evaluation of Teaching Effectiveness in Saudi Higher Education : The Case of Jubail University College," vol. 5, no. 5, pp. 464-475, 2017, doi: 10.12691/education-5-5-2.

[41]. D. Gefen, D. Straub, and M.-C. Boudreau, "Structural Equation Modeling and Regression: Guidelines for Research Practice," vol. 4, no. October, 2000, doi: 10.17705/1CAIS.00407.

[42]. C. Fornell and D. F. Larcker, "Evaluating Structural Equation Models with Unobservable Variables and Measurement Error," J. Mark. Res., vol. 18, no. 1, pp. 39-50, 1981, doi: doi.org/10.1177\%2F002224378101800104.

[43]. J. C. Nunnally, Psychometric theory by] Jum C. Nunnally. New York: McGraw-Hill, 1967.

[44]. J. F. Hair, G. T. M. Hult, C. M. Ringle, and M. Sarstedt, Partial Least Squares Structural Equation Modeling, no. September. 2014.

[45]. J. Henseler, C. M. Ringle, and M. Sarstedt, "A new criterion for assessing discriminant validity in variance-based structural equation modeling," J. Acad. Mark. Sci., vol. 43, pp. 115135, 2015, doi: 10.1007/s11747-014-0403-8.

[46]. J. F. Hair, C. M. Ringle, and M. Sarstedt, "PLSSEM: Indeed a silver bullet," J. Mark. Theory Pract., vol. 19, no. 2, pp. 139-152, 2011, doi: 10.2753/MTP1069-6679190202. 
[47]. J. Cohen, Statistical power analysis for the behavioral sciences. Hillsdale, N.J.: L. Erlbaum Associates, 1988.

[48]. K. Hardcastle, M. A. Bellis, K. Ford, K. Hughes, J. Garner, and G. Ramos Rodriguez, "Measuring the relationships between adverse childhood experiences and educational and employment success in England and Wales: findings from a retrospective study," Public Health, vol. 165, pp. 106-116, 2018, doi: 10.1016/j.puhe.2018.09.014.

[49]. L. $\mathrm{Hu}$ and P. M. Bentler, "Fit indices in covariance structure modeling: Sensitivity to underparameterized model misspecification.," Psychol. Methods, vol. 3, no. 4, pp. 424-453, 1998, doi: 10.1037/1082-989X.3.4.424.

[50]. J. Khalilzadeh, A. B. Ozturk, and A. Bilgihan, "Security-related factors in extended UTAUT model for NFC based mobile payment in the restaurant industry," Comput. Human Behav., vol. 70, no. 2017, pp. 460-474, 2017, doi: 10.1016/j.chb.2017.01.001.

[51]. A. Nunes, T. Limpo, and S. L. Castro, "Acceptance of Mobile Health Applications: Examining Key Determinants and Moderators," Front. Psychol., vol. 10, no. December, pp. 1-9, 2019, doi: 10.3389/fpsyg.2019.02791.

[52]. P. P. Ofori, E. A. Antwi, and K. A. Owusu-ansah, "The mediating effects of satisfaction and attitude on consumers ' intent toward adoption of social media healthcare information," J. Heal. Soc. Sci., vol. 6, no. 3, pp. 391-402, 2021, doi: $10.19204 / 2021 /$ thmd5.

[53]. J. W. Lian and D. C. Yen, "Online shopping drivers and barriers for older adults: Age and gender differences," Comput. Human Behav., vol. 37, pp. 133-143, 2014, doi: 10.1016/j.chb.2014.04.028.

[54]. L. Deng, D. E. Turner, R. Gehling, and B. Prince, "User experience, satisfaction, and continual usage intention of IT," Eur. J. Inf. Syst., vol. 19, no. 1, pp. 60-75, 2010, doi: 10.1057/ejis.2009.50.
[55]. G. Luna-Cortés, J. M. López-Bonilla, and L. M. López-Bonilla, "Self-Congruity, Social Value, and the Use of Virtual Social Networks by Generation Y Travelers," J. Travel Res., vol. 58, no. 3, pp. 398-410, 2019, doi: $10.1177 / 0047287518755502$.

\section{Cite this article as :}

Philomina P. Ofori, Ethel Asante Antwi, Adelaide Oduro-Asante, "The Behavioral Intention in Accessing Digital Healthcare Information on Social Media", International Journal of Scientific Research in Science and Technology (IJSRST), Online ISSN : 2395-602X, Print ISSN : 2395-6011, Volume 8 Issue 6, pp. 510-521, November-December 2021. Available at doi $\quad$ : https://doi.org/10.32628/IJSRST218673

Journal URL : https://ijsrst.com/IJSRST218673 